OPEN ACCESS

Edited by:

Ali Bajwa,

New South Wales Department of Primary Industries, Australia

Reviewed by: Ahmet Uludag, Çanakkale Onsekiz Mart University, Turkey Puja Ray,

Presidency University, India

Katherine Waselkov,

California State University,

United States

*Correspondence:

Heinz Müller-Schärer

heinz.mueller@unifr.ch

Specialty section:

This article was submitted to

Weed Management,

a section of the journal

Frontiers in Agronomy

Received: 04 November 2020 Accepted: 31 December 2020 Published: 09 February 2021

Citation:

Sun Y, Kaleibar BP, Oveisi M and Müller-Schärer H (2021) Addressing

Climate Change: What Can Plant Invasion Science and Weed Science

Learn From Each Other?

Front. Agron. 2:626005.

doi: 10.3389/fagro.2020.626005

\section{Addressing Climate Change: What Can Plant Invasion Science and Weed Science Learn From Each Other?}

\author{
Yan Sun ${ }^{1}$, Behnaz Pourmorad Kaleibar ${ }^{2}$, Mostafa Oveisi ${ }^{2}$ and Heinz Müller-Schärer ${ }^{1,2 *}$ \\ ${ }^{1}$ Department of Biology, University of Fribourg, Fribourg, Switzerland, ${ }^{2}$ Agronomy and Plant Breeding Department, University \\ of Tehran, Karaj, Iran
}

Plant invasion science and weed science, both dealing with harmful plants, have historically developed in separation. This may also be true for how the two fields are addressing the consequences of future climate change. Here, we first conducted a literature survey to explore how researchers in these two disciplines study the effects of climate change, and then identified their characteristic approaches to determine what the disciplines can learn from each other to better understand, predict, and mitigate the outcomes of responses of harmful plants to climate change. Over the past 20 years, we found a much steeper increase in publications dealing with climate change for invasive alien plants (IAP) than for weeds. However, invasion scientists have to date only rarely investigated climate change effects at the local scale, such as on functional traits and population dynamics. In contrast, weed science could benefit from studies at larger scale, such as using a modeling approach to predict changes in weed distributions. Studies assessing the impacts of the target plants on ecosystem properties and on society, and on their management under climate change are important components of weed studies but remain neglected for IAP. This is despite an urgent need, especially because under climate change, abandoned cropland, and areas of high conservation value are facing increasing risk from IAP. We argue that the strengths and diversity of approaches of these two disciplines in studying the effects of climate change are complementary and that closer ties between them would be highly beneficial for both.

\footnotetext{
Keywords: impact, invasive alien plants, literature survey, management, publication metrics, research questions, study method, weeds
}

\section{INTRODUCTION}

Plant invasion science is a relatively new research field dealing with the causes and consequences of organisms introduced into and invading areas outside their native range, and in the case of plants, mostly on species that conquer semi-natural and natural ecosystems. It is mainly driven by fundamental scientific questions and ecological theories, also by the practice of conservation, with a focus on community, ecosystem, and biogeography (Kueffer et al., 2013). In contrast, weed science has a long tradition supported by agronomy with good links to the private sector, and is mainly driven by practical management and control questions, and innovations in agricultural engineering (Hall et al., 2000; Fernandez-Quintanilla et al., 2008; Jordan et al., 2016). Its main focus is on cultivated land (i.e., the land used for producing major food and animal feed, including perennial crops and managed grassland) and the reduction of biomass at a site. This distinct history, focus, 
and approach between the two disciplines have recently been further elaborated by Müller-Schärer et al. (2018). Here we hypothesize that these differences between the two disciplines might also be evident on how consequences of future climate change for harmful plants and their management are being addressed. We acknowledge that both invasion and weed science also deal with harmful plants at historical places, in cities, and along linear transport structures, such as roads, railway tracts, and rivers, although not being their main focus. To account for and repeal this overlap, we excluded these habitat types in our literature survey.

Anthropogenic climate changes driven by greenhouse gas emissions include increases in temperature and $\mathrm{CO}_{2}$ emissions, changing patterns of precipitation and the severity, and frequency of extreme climatic events (i.e., drought, flood, fires, intense storms, and heat waves). These changes are predicted to select on means and plasticities of plant traits and vital rates to better cope with these changing environmental conditions, with consequences for competitive interactions, local abundances, spread and impact on plant communities and ecosystems, and ultimately on ecosystem services and people's livelihoods (Vilà et al., 2007). Climate change, especially effects of increased $\mathrm{CO}_{2}$ and temperature have been postulated to affect weed germination, emergence pattern, their competitive ability, and thus, also crop yield, but yet few studies experimentally addressed climate change effects on weed growth, water limitations, or herbicide efficiency (Ziska, 2016). Decreasing efficiency of herbicides under climate change may lead to an increased risk for the evolution of herbicide-resistant weeds (Matzrafi et al., 2016). Thus, for both invasive alien plants (IAP in the following) and weeds, these changes will also create a need for adapted control strategies as part of mitigation planning (Chauhan, 2020). This offers a wide range of climate features to elaborate upon, a variety of study questions and methods, and a multitude of impacts and outcomes to study, ranging from changes in functional traits, population dynamics, and distribution of the harmful plants up to their consequences for crop yield and ecosystem services. Here, we first conduct a literature survey to explore if and how studies on IAP differ from crop and grassland weeds when considering effects of climate change. These findings allow us then to identify the strengths and gaps, as well as the commonalities and differences when studying climate change effects in these disciplines, and to derive what can be learnt from each other for understanding, predicting, and mitigating outcomes of climate change.

\section{STUDY PROCEDURE}

For our literature survey, we used the search term combinations " $\{\mathrm{AB}=[$ (climate change OR climatic change OR warming) AND (invasive plant OR plant inva ${ }^{*}$ )] AND TS $=$ (introduced OR exotic OR alien)\} AND DOCUMENT TYPES: (Article) Timespan $=2000-2020$ " and " $\{\mathrm{AB}=[$ (climate change OR climatic change OR warming) AND (weed)] AND TS $=$ (crop OR grassland) $\}$ AND DOCUMENT TYPES: (Article) Timespan $=2000-2020$ " on the ISI Web of Knowledge database on July 23, 2020 for relevant articles on IAP and weeds, respectively. In our search, we found no studies of alien weeds in grassland ecosystems matching our criteria, but a total of 21 out of 65 studies on alien crop weeds, thus delimiting the studies of the two disciplines mainly based on the habitat type where the harmful species occur i.e., seminatural and natural vs. cultivated habitats (cf. e.g., Holzner and Glauninger, 2005; Follak et al., 2017; Fried et al., 2017). In the following, we therefore mainly use the term disciplines for the separation of the two searches.

Our survey resulted in an initial set of 616 and 407 articles for IAP and weeds, respectively. To minimize assessor biases (González-Moreno et al., 2019), all co-authors first reviewed and classified the same 100 publications. Discrepancies between the assessors were discussed to reach a consensus and to establish a standard protocol for each category before the main assessor examined each publication to first decide whether it is meeting the selection criteria for inclusion in the review. The main criterion for our selection was that the studies quantitatively address the effects of climate change features on the target plant species, on the target plant's impact on ecosystem properties and the society, and on their management interventions. A total of 179 articles representing 204 case studies of IAP and 45 articles representing 65 case studies of weeds across 47 plant families met our criteria. For these, we assessed a total of seven categories with each 5-7 sub-categories (cf. Figures 1B, 2): publication metrics (publication year, impact factor of the published journal, number citations, publication activity, country of the first author, research area, number of institutions listed in authors' affiliation), climate features studies [modeled data using multiple climate features, experimentally testing temperature, $\mathrm{CO}_{2}$, precipitation, fire, and others (i.e., salinity, shade, and nitrogen)], taxonomic classification of IAP and weeds, research question (i.e., effects of climate change on target IAP/weed: functional and morphological traits, population dynamics, distribution or niche, abundance and evolutionary changes), study method (observation/interview, field manipulative experiment, common garden experiment, omics tool, modeling, and meta-analysis), impact of the target plants (on resident community, trophic interaction, crop yield, infrastructure, human welfare, and economy), and management of the target plants (prevention, competition, eradication, physical control, chemical control, and biological control). Uncertainties of the main assessor (BPK) in doing these classifications were discussed as they came up with two co-authors (YS and HM-S) to reach a consensus score.

All statistical analyses were done in $\mathrm{R}$ version 3.6.0 ( $\mathrm{R}$ Development Core Team, 2019). The relative similarity of the studies in two disciplines was compared using a non-metric multidimensional scaling (NMDS) ordination on Bray Curtis distance among the study characteristics using the dissimilarity for mixed variables, obtained from gow dis function in $F D$ package (Laliberté et al., 2014) that implements Podani (1999) extension to ordinal variables. To determine whether the ordination obtained by NMDS was significantly correlated with the two disciplines, we fit discipline as a factor to all ordinations by the "envfit" function in the VEGAN package (Oksanen et al., 2007). We used $n=9,999$ permutations for the envfit permutation testing procedure. We then performed chi-square tests to analyze 

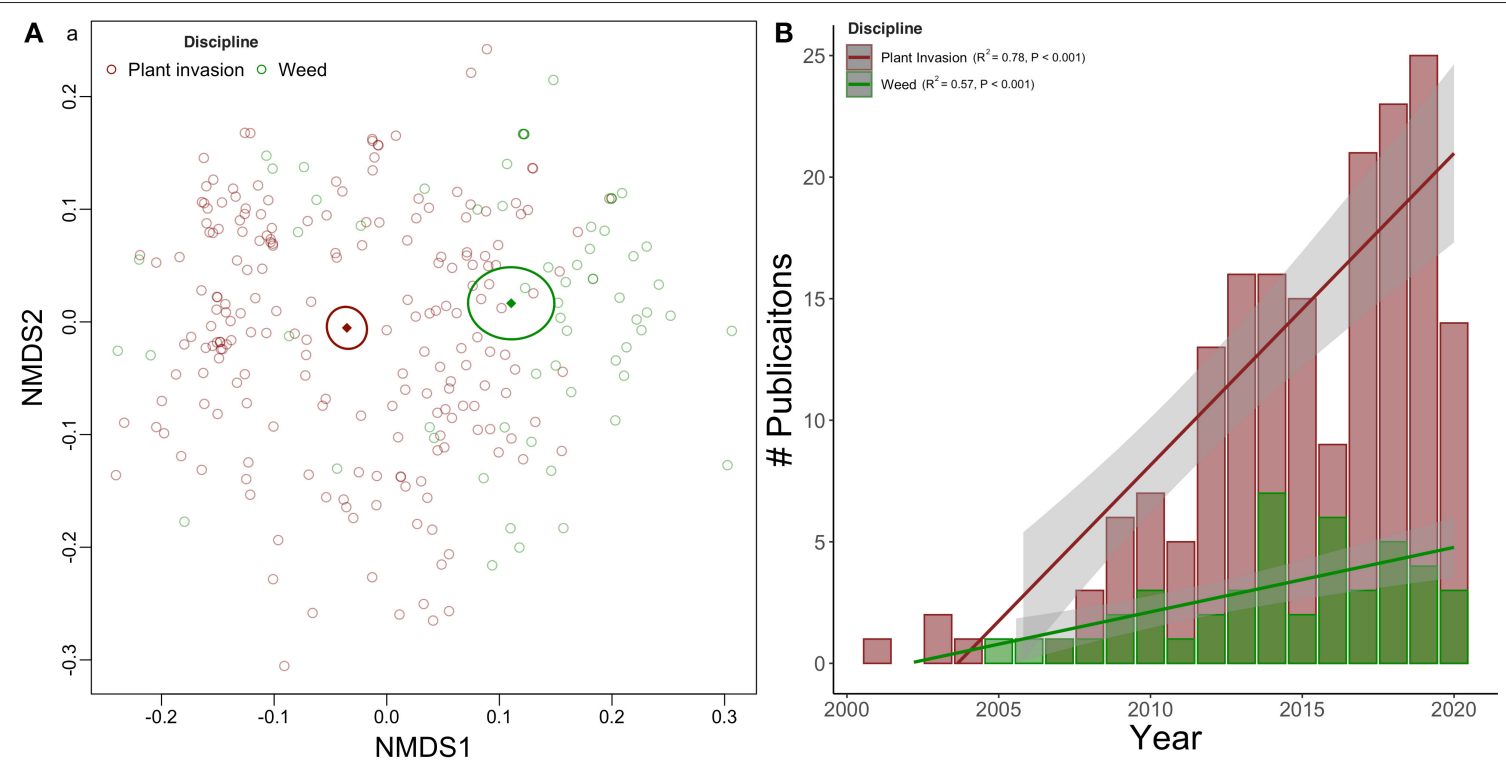

FIGURE 1 | (A) Non-metric multidimensional scaling (NMDS) ordination of the overall compositions of the study categories and sub-categories of the two disciplines based on Bray-Curtis dissimilarities (stress $=0.15$ ). Points represent individual studies, and ellipses represent standard errors (SE) around the mean centroid of each discipline. (B) Number of publications per year that address climate change features for the two disciplines with their linear regression line.

the differences in categories/subcategories between the two disciplines. We analyzed the continuous data (e.g., cited time, activities) with linear mixed models, using the lmer functions in the R package lme 4 and maximum likelihood to estimate model parameters (Bates et al., 2014), which include discipline as a fixed factor and publication year as a random factor.

\section{STUDYING INVASIVE ALIEN PLANTS VS. WEEDS UNDER CLIMATE CHANGE}

Based on all pairwise rank order comparisons for all study categories and their sub-categories, NMDS ordination allows for a visualization of the overall distance between the two disciplines in studying climate change effects. The NMDS plot shows a clear separation along the first dimension $(P<0.001$; Figure 1A), thus indeed, plant invasion science and weed science use different research methods to address different aspects of the target plants when studying consequences of future climate change. The publication metrics significantly differ between the two disciplines (Figure 1B). Over the past 20 years, there is an overall increase in publications per year studying climate change effects in both disciplines, but a much steeper increase in publications dealing with IAP than with weeds, reaching 25 publications per year for the former as compared to only four for the latter in 2019 (Figure 1B). Linked to this, average citations per publication over this period (20.5 vs. $16.9, P=0.03)$ and overall activities (number of times the full text of a record has been accessed or a record has been saved since February 1, 2013; 58.86 vs. $39.45, P<0.001$ ) were also much higher for IAP than for weeds. In line with this, also the average impact factor of the publication journal was higher for the plant invasion than the weed science discipline (3.67 vs. $2.81, P=0.009$ ). The average number of authors per publication did not differ between the two disciplines ( 4.72 vs. $4.75, P=0.82$ ), but the average number of institutions per publication was higher for the plant invasion than the weed science discipline ( 3.41 vs. $2.65, P=0.03$ ).

For all other categories and sub-categories, we then compared the relative contribution of sub-categories within each category for both IAP and weeds, and the relative numbers of studies within each category between the two disciplines. Based on the continent given for the first author, the relative number of climate change studies in the various continents did not differ between the two disciplines $(P=0.12)$, with first authors in both disciplines more often coming from Europe and America, and least often from Africa (Figure 2A). Moreover, only 10 studies dealt with non-angiosperms (four Pinaceae, five Salviniaceae, and one Caulerpaceae), all IAP. Among the angiosperms, monocots, compared to dicots are less often studied in plant invasion than in weed science $(P=0.006$; Figure $2 B$ ). The relative numbers of the various climate features studied differed between disciplines $(P=0.008)$, with the highest proportion of modeling studies for IAP, and with relatively more studies investigating effects of experimentally testing temperature, $\mathrm{CO}_{2}$, and fire in weeds than in IAP (Figure 2C). The research questions $(P=0.002)$ and study methods $(P<0.001)$ also differed between the two disciplines, with traits and population dynamics being relatively more often assessed for weeds than for IAP, while plant distribution is more often studied for IAP. Among all study methods, a modeling approach using multiple climate features was most often used in both disciplines, but the relative importance within disciplines was higher for IAP with $57 \%$ of the methods used as compared to $38 \%$ for weeds (Figures 2D,E). Climate change effects was assessed in only 31 studies of IAP and 23 studies of weeds, thus 


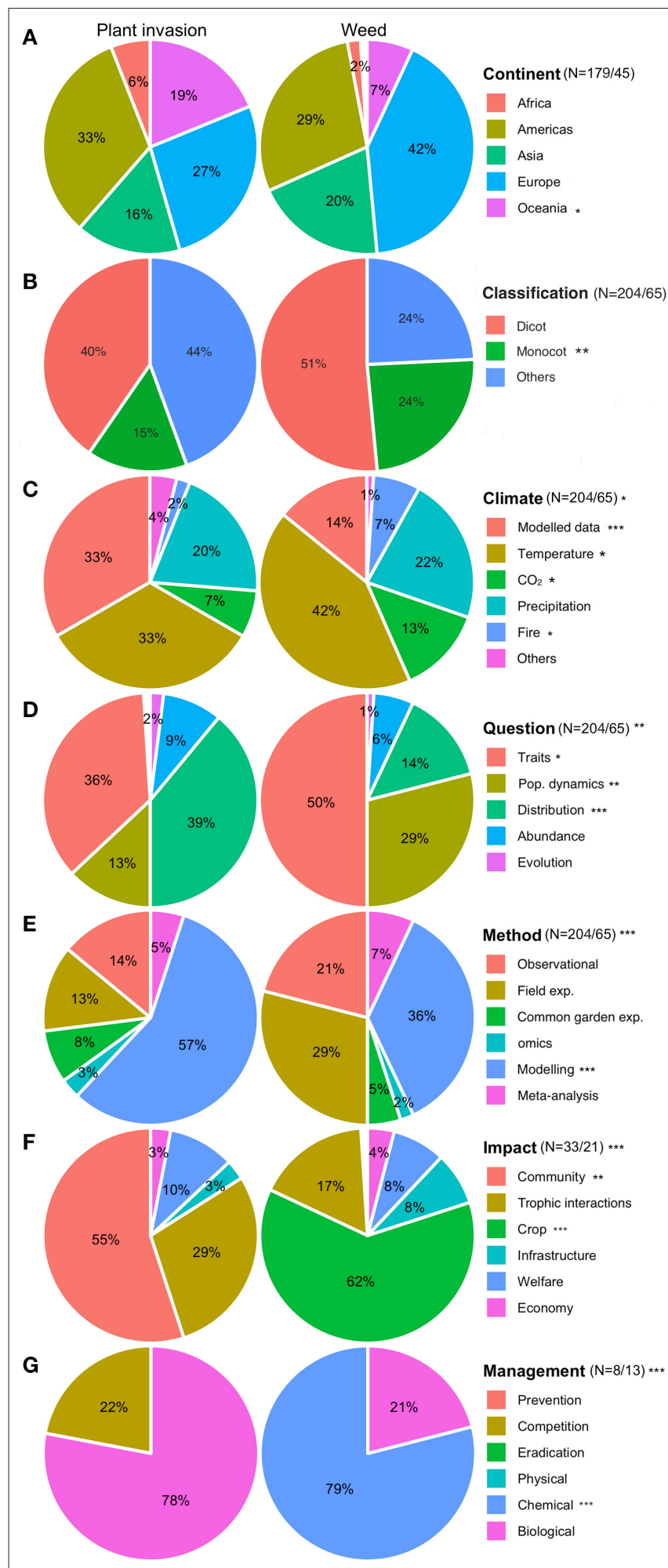

FIGURE 2 | Relative abundance of subcategories within each category for both plant invasion and weed science, and number of studies and comparisons between the disciplines, with ${ }^{* * *} p \leq 0.001,{ }^{* *} p \leq 0.01,{ }^{*} p \leq 0.05$, empty: $p>0.05$. (A) Continent of the first author, (B) study plant classification, (C) climate feature studied, (D) research question, (E) main method used, (F) assessed impact, and (G) evaluated management intervention. yet twice as often in weeds (32\%) than in IAP studies (16\%). Not surprisingly, community impact of the target plant was studied most often in IAP (55\%), whereas impact on crops most often in weeds (58\%). Trophic interactions were also studied twice as often in IAP (31\%) than in weeds (15\%), but this difference was not statistically significant (Figure 2F). Finally, effects of climate change on management still remains only little studied, but relatively more often in weeds (18\%) than in IAP (4\%), with studies addressing climate change of chemical control dominating the management interventions of weeds (Figure 2G).

\section{SYNERGIZING THE STRENGTHS OF THE TWO DISCIPLINES TO THE BENEFIT OF BOTH}

We are well aware that the distinction between plant invasion and weed science is getting blurred in many countries as the two disciplines are coming increasingly closer together, but our survey yet confirmed, clear differences between them on how they study the effects of climate change. Identifying knowledge gaps in the two disciplines resulting from our literature survey will help to guide discipline-specific future (experimental) research in order to better predict, understand, and hence mitigate climate change effects mediated by potentially favoring harmful plants.

We found distinct differences in the publication metrics between the two disciplines with regard to how often climate change is being addressed. The higher number of publications over the past 20 years on IAP as compared to weeds (179 vs. 45) that address climate change may reflect on the one hand the increased interest of the society due to the ever increasing number of IAP worldwide, and their huge impact on the economy and ecosystems (Seebens et al., 2017), and of researchers in basic ecology and evolution studying the specific features that plant populations offer when introduced to novel abiotic and biotic habitats (Callaway and Maron, 2006). This is mirrored, e.g., in dedicated sessions on plant invasions at nearly every international symposium in ecology, conservation biology, biogeography, and evolution, and also explains the increased activities and impact factor of the journals in which studies of the IAP compared to weeds are being published. On the other hand, weed science, especially in Europe, has experienced a steady decline of active weed scientists over the past few decades (Fernandez-Quintanilla et al., 2008; cf. Müller-Schärer et al., 2018 for more details). Opening-up the scope in weed science from close ties to agriculture to address new issues such as global warming, invasive alien species, and client diversification is presently ongoing (Chauhan, 2020; https://www.ewrs.org/en/pages/WeedResearch-Themes). This may lead to the initiation of more interdisciplinary studies on weeds that will result in increased visibility also through enhanced coverage in more highly cited journals. In this respect, the higher average number of institutions per publication for the plant invasion science than the weed science discipline addressing climate change 
features may indicate larger and already better-established interdisciplinary networks in plant invasion science as compared to weed science.

The fact that climate change studies are predominantly headed by researchers from Europe, followed by America and Asia, and least in Africa, as based on continent of the first author (Figure 1A), may reflect that the re-orientation in weed science toward including, among others, climate change issues, is still less advanced in Asia and Africa (Ward et al., 2014).

Our finding that monocots are relatively more often studied in weed science than in invasion science is not surprising given the high number of monocot weeds in crop and grassland habitats as compared alien monocot species in non-crop habitats (Daehler, 1998). Main plant traits and responses driving population dynamics range from seed fate in the seed bank (Walck et al., 2011), physiological seed dormancy (Ooi et al., 2012), and accordingly seedling emergence pattern (Classen et al., 2010), relative growth rate (Bütof et al., 2012), morphological characteristics (Guerin et al., 2012) up to canopy structure (Pangga et al., 2013), seed production (Nguyen et al., 2017), environment maternal effects (Dwyer and Erickson, 2016), and shifts in the weed flora (Peters et al., 2014), all being sensitive to climate change effects. Climate change is expected to also highly influence herbicide effects via changing herbicide uptake, translocation, and metabolism (Varanasi et al., 2016). This may also break herbicide selectivity and cause crop damage (Jursík et al., 2020). Furthermore, resistant populations are expected to arise via changes in herbicide effects under climate change conditions (Refatti et al., 2019). However, climate change features on weed biology often have been studied in isolation, focusing on increase in temperature or $\mathrm{CO}_{2}$ only, and although such basic knowledge is getting more readily available, so far only few studies are addressing practical implementations to mitigate climate change effects. Invasion scientists so far only rarely investigated processes at a local range, such as plant traits and the population dynamics of IAP. On the other hand, modeling studies, often based on latitudinal or altitudinal climate gradients, have been used more often in plant invasion science, but could also be explored more often by weed scientists to address expected outcomes of climate change at a larger spatial scale.

Studies on the impact of the target plants and on their management must be an important component of weed studies under climate change, as weed science, fundamentally, has been founded on the basis of weed management. Any study on biology, evolution, ecology, physiology, and population genetics is eventually looking for an approach to managing weeds (Zimdahl, 2018). In line with this, the main conclusions in weed science publications are expected to end up with a recommendation to manage undesirable vegetation (https:// www.cambridge.org/core/journals/weed-science/information/ instructions-for-authors). On the other hand, impact and management studies remain greatly neglected in plant invasion science (Figure 2G). Invasion science has recently made significant progress in classifying and conceptualizing invasion processes (Wilson et al., 2020) and in documenting the increasing number of invasions worldwide coupled with ever increasing costs for the society, but these achievements are of little help to practitioners confronted with alien invasive plants (Plank et al., 2016; Nkambule et al., 2017; Zhang et al., 2020). Thus, an increased focus on specific ecosystem and society impacts of the target plant and on its management is greatly in need when exploring outcomes of climate change for IAP, especially to mitigate climate change effects for areas of high conservation value presently under great risk from IAP (Slodowicz et al., 2018).

Clearly, both disciplines could greatly benefit from more evolutionary studies investigating changes in the genetic composition within and among populations, thus both at the local and larger regional scale. Rapid increases in herbicide resistance have highlighted the ability of weeds to undergo rapid evolutionary change, but as shown in a recent review by Ziska et al. (2019), genetic changes in weed populations in response to the rapid rise in atmospheric carbon dioxide $\left(\mathrm{CO}_{2}\right)$ and other associated changes in climate are only rarely studied, but most likely to occur, with consequences for the distribution, community composition, and herbicide efficacy. Similarly, Müller-Schärer et al. (2020) and Sun et al. (2020b) reviewed the increasing yet limited evidence of rapid postintroduction evolution in IAP, and Sun et al. (2020c) and Sun et al. (2020a) reviewed and discussed the potential ecological and evolutionary outcomes for biological control management, and its efficacy under present and future climate conditions. A better understanding of such evolutionary processes will improve our prediction of the adaptive potential, future spread and management outcomes of harmful plants under climate change.

It remains to be further explored on how the recipient communities may also be affected by climate change, either directly (e.g., drought stress) or indirectly (e.g., change in land use), which in turn will affect their susceptibility to, or impact on, weeds and IAP. For instance, some of the worst weed invasions in Wyoming (Cramer et al., 2008) and Ethiopia (Dong et al., 2011; Degefa and Soromessa, 2015) occurred in areas where a reduction in rainfall during the twentieth century led to the abandonment of crop production; these habitats with a history of soil disturbance were then overrun by invasive alien plants. Also, crop species or varieties that use less water now being used to mitigate climate change effects might also differently respond to, or being impacted by, weed species. Under climate change, populations of IAP may either migrate to follow suitable environmental conditions in space without evolving, or they might locally adapt to novel climatic conditions, with or without migrating (Polechová et al., 2009; Sun et al., 2020b). The relative importance of these two scenarios is still unclear. In weed management, the expected accelerated evolution of herbicide resistance under climate change, increased herbicide regulations (e.g., the ban of numerous acting ingredients of herbicides) and a reduction in the discovery of new active ingredients of herbicides, is presently moving the field from herbicide dominated weed management to Integrated Weed Management (IWM). How the 
outcome of such changes will be modulated by climate change, still needs to be explored (Neve et al., 2009). To answer these pressing questions in view of mitigating the expected increasing impact of harmful plants on the environment and economy under climate change, joint efforts across disciplines and country are urgently needed.

Presently, in most countries, the two research fields are indeed coming closer together, also as typical IAP are increasingly reported from crop fields and native crop weeds are invading adjacent non-crop land that, under climate change, may become more suitable to the growth and development of certain weed species. Thus, target habitats will increasingly overlap, which earlier separated the two disciplines (Müller-Schärer et al., 2018). This offers increased opportunities to jointly address issues of harmful plants and by this, to synergize the strength of the two disciplines. Only this joint effort may bring real advances in understanding, predicting, and mitigating climate change effects for both IAP and weeds.

\section{REFERENCES}

Bates, D., Maechler, M., Bolker, B., Walker, S., Christensen, R. H. B., Singmann, H., et al. (2014). Package 'Ime4'. R Foundation for Statistical Computing, Vienna.

Bütof, A., von Riedmatten, L. R., Dormann, C. F., Scherer-Lorenzen, M., Welk, E., and Bruelheide, H. (2012). The responses of grassland plants to experimentally simulated climate change depend on land use and region. Glob. Chang. Biol. 18, 127-137. doi: 10.1111/j.1365-2486.2011.02539.x

Callaway, R. M., and Maron, J. L. (2006). What have exotic plant invasions taught us over the past 20 years? Trends Ecol. Evol. 21, 369-374. doi: $10.1016 /$ j.tree.2006.04.008

Chauhan, B. (2020). Grand challenges in weed management. Front. Agron. 1:3. doi: 10.3389 /fagro.2019.00003

Classen, A. T., Norby, R. J., Sides, K. E., and Weltzin, J. F. (2010). Climate change alters seedling emergence and establishment in an old-field ecosystem. PLoS ONE 5:e13476. doi: 10.1371/journal.pone.0013476

Cramer, V. A., Hobbs, R. J., and Standish, R. J. (2008). What's new about old fields? Land abandonment and ecosystem assembly. Trends Ecol. Evol. 23, 104-112. doi: $10.1016 /$ j.tree.2007.10.005

Daehler, C. C. (1998). The taxonomic distribution of invasive angiosperm plants: ecological insights and comparison to agricultural weeds. Biol. Conserv. 84, 167-180. doi: 10.1016/S0006-3207(97)00096-7

Degefa, S., and Soromessa, T. (2015). Invasive and exotic species in the restoration of stochastic agricultural lands in Ethiopia. Adv. Life Sci. Technol. 35, 72-77. doi: $10.7176 /$ ALST

Dong, S., Wen, L., Liu, S., Zhang, X., Lassoie, J. P., Yi, S., et al. (2011). Vulnerability of worldwide pastoralism to global changes and interdisciplinary strategies for sustainable pastoralism. Ecol. Soc. 16:10. doi: 10.5751/ES-04093-160210

Dwyer, J. M., and Erickson, T. E. (2016). Warmer seed environments increase germination fractions in Australian winter annual plant species. Ecosphere 7:e01497. doi: 10.1002/ecs2.1497

Fernandez-Quintanilla, C., Quadranti, M., Kudsk, P., and Barberi, P. (2008). Which future for weed science? Weed Res. 48, 297-301. doi: $10.1111 / j .1365-3180.2008 .00642 . x$

Follak, S., Schleicher, C., Schwarz, M., and Essl, F. (2017). Major emerging alien plants in Austrian crop fields. Weed Res. 57, 406-416. doi: 10.1111/wre.12272

Fried, G., Chauvel, B., Reynaud, P., and Sache, I. (2017). "Decreases in crop production by non-native weeds, pests, and pathogens," in Impact of Biological Invasions on Ecosystem Services, eds M. Vilà and P. E. Hulme (Cham: Springer), 83-101.

González-Moreno, P., Lazzaro, L., Vilà, M., Preda, C., Adriaens, T., Bacher, S., et al. (2019). Consistency of impact assessment protocols for non-native species. NeoBiota 44, 1-25. doi: 10.3897/neobiota.44.31650

\section{AUTHOR CONTRIBUTIONS}

YS, HM-S, and MO designed the study. BK did most of the data retrieval. YS did the statistical analyses. YS and HM-S wrote the first version of the manuscript. All authors contributed to the final version.

\section{ACKNOWLEDGMENTS}

We thank Urs Schaffner for critically commenting on an earlier version of this paper. We also thank the Center of Excellence of Weeds and invasive plants management under climate change of the University of Tehran for their support. We acknowledge the Swiss National Science Foundation (project number 31003A_166448) to HM-S, the Swiss State Secretariat for Education, Research and Innovation \#C13.0146 to HM-S), and the Swiss Federal Office for the Environment (13.0098.KP/M3230760 to HM-S).

Guerin, G. R., Wen, H., and Lowe, A. J. (2012). Leaf morphology shift linked to climate change. Biol. Lett. 8, 882-886. doi: 10.1098/rsbl.2012.0458

Hall, J. C., Van Eerd, L. L., Miller, S. D., Owen, M. D., Prather, T. S., Shaner, D. L., et al. (2000). Future research directions for weed science. Weed Technol. 14, 647-658. doi: 10.1614/0890-037X(2000)014[0647:FRDFWS]2.0.CO;2

Holzner, W., and Glauninger, J. (2005). Ackerunkräuter: Bestimmung, Biologie, Landwirtschaftliche Bedeutung. Graz: Leopold Stocker Verlag.

Jordan, N., Schut, M., Graham, S., Barney, J., Childs, D., Christensen, S., et al. (2016). Transdisciplinary weed research: new leverage on challenging weed problems? Weed Res. 56, 345-358. doi: 10.1111/wre.12219

Jursík, M., Kočárek, M., Kolárová, M., and Tichý, L. (2020). Effect of different soil and weather conditions on efficacy, selectivity and dissipation of herbicides in sunflower. Plant Soil Environ. 66, 468-476. doi: 10.17221/223/2020-PSE

Kueffer, C., Pyšek, P., and Richardson, D. M. (2013). Integrative invasion science: model systems, multi-site studies, focused meta-analysis and invasion syndromes. New Phytol. 200, 615-633. doi: 10.1111/nph.12415

Laliberté, E., Legendre, P., Shipley, B., and Laliberté, M. E. (2014). Package 'FD'. Measuring Functional Diversity From Multiple Traits, and Other Tools for Functional Ecology. Available online at: https://cran.rstudio.org/web/packages/ FD/FD.pdf

Matzrafi, M., Seiwert, B., Reemtsma, T., Rubin, B., and Peleg, Z. (2016). Climate change increases the risk of herbicide-resistant weeds due to enhanced detoxification. Planta 244, 1217-1227. doi: 10.1007/s00425-0162577-4

Müller-Schärer, H., Bouchemousse, S., Litto, M., McEvoy, P. B., Roderick, G. K., and Sun, Y. (2020). How to better predict long-term benefits and risks in weed biocontrol: an evolutionary perspective. Curr. Opin. Insect Sci. 38, 84-91. doi: 10.1016/j.cois.2020.02.006

Müller-Schärer, H., Sun, Y., Chauvel, B., Karrer, G., Kazinczi, G., Kudsk, P., et al. (2018). Cross-fertilizing weed science and plant invasion science to improve efficient management: a European challenge. Basic Appl. Ecol. 33, 1-13. doi: 10.1016/j.baae.2018.08.003

Neve, P., Vila-Aiub, M., and Roux, F. (2009). Evolutionary-thinking in agricultural weed management. New Phytol. 184, 783-793. doi: 10.1111/j.1469-8137.2009.03034.x

Nguyen, T., Bajwa, A. A., Navie, S., O'donnell, C., and Adkins, S. (2017). Parthenium weed (Parthenium hysterophorus L.) and climate change: the effect of $\mathrm{CO} 2$ concentration, temperature, and water deficit on growth and reproduction of two biotypes. Environ. Sci. Pollut. Res. 24, 10727-10739. doi: 10.1007/s11356-017-8737-7

Nkambule, N. P., Blignaut, J. N., Vundla, T., Morokong, T., and Mudavanhu, S. (2017). The benefits and costs of clearing invasive alien plants in northern Zululand, South Africa. Ecosystem Serv. 27, 203-223. 
Oksanen, J., Kindt, R., Legendre, P., O’Hara, B., Stevens, M. H. H., Oksanen, M. J., et al. (2007). The vegan package. Commun. Ecol. Pack. 10, 631-637. doi: 10.1007/978-3-319-45121-3_6

Ooi, M. K., Auld, T. D., and Denham, A. J. (2012). Projected soil temperature increase and seed dormancy response along an altitudinal gradient: implications for seed bank persistence under climate change. Plant Soil 353, 289-303. doi: 10.1007/s11104-011-1032-3

Pangga, I. B., Hanan, J., and Chakraborty, S. (2013). Climate change impacts on plant canopy architecture: implications for pest and pathogen management. Eur. J. Plant Pathol. 135, 595-610. doi: 10.1007/s10658-012-0118-y

Peters, K., Breitsameter, L., and Gerowitt, B. (2014). Impact of climate change on weeds in agriculture: a review. Agron. Sustain. Dev. 34, 707-721. doi: 10.1007/s13593-014-0245-2

Plank, L., Zak, D., Getzner, M., Follak, S., Essl, F., and Dullinger, S., et al. (2016). Benefits and costs of controlling three allergenic alien species under climate change and dispersal scenarios in Central Europe. Environ. Sci. Policy, 56, 9-21.

Podani, J. (1999). Extending Gower's general coefficient of similarity to ordinal characters. Taxon 48, 331-340. doi: 10.2307/1224438

Polechová, J., Barton, N., and Marion, G. (2009). Species' range: adaptation in space and time. Am. Nat. 174, E186-E204. doi: 10.1086/605958

R Development Core Team. (2019). R: A Language and Environment for Statistical Computing. R Foundation for Statistical Computing. Available online at: https://www.R-project.org/

Refatti, J. P., de Avila, L. A., Camargo, E. R., Ziska, L. H., Oliveira, C., SalasPerez, R., et al. (2019). High [CO2] and temperature increase resistance to cyhalofop-butyl in multiple-resistant Echinochloa colona. Front. Plant Sci. 10:529. doi: 10.3389/fpls.2019.00529

Seebens, H., Blackburn, T. M., Dyer, E. E., Genovesi, P., Hulme, P. E., Jeschke, J. M., et al. (2017). No saturation in the accumulation of alien species worldwide. Nat. Commun. 8:14435. doi: 10.1038/ncomms 14435

Slodowicz, D., Descombes, P., Kikodze, D., Broennimann, O., and Müller-Schärer, H. (2018). Areas of high conservation value at risk by plant invaders in Georgia under climate change. Ecol. Evol. 8, 4431-4442. doi: 10.1002/ece3.4005

Sun, Y., Beuchat, C., and Müller-Schärer, H. (2020a). Is biocontrol efficacy rather driven by the plant or the antagonist genotypes? A conceptual bioassay approach. NeoBiota 63:81. doi: 10.3897/neobiota.63.54962

Sun, Y., Bossdorf, O., Grados, R. D., Liao, Z., and Müller-Schärer, H. (2020b). Rapid genomic and phenotypic change in response to climate warming in a widespread plant invader. Global Change Biol. 26, 6511-6522. doi: $10.1111 /$ gcb.15291

Sun, Y., Ding, J., Siemann, E., and Keller, S. R. (2020c). Biocontrol of invasive weeds under climate change: progress, challenges and management implications. Curr. Opin. Insect Sci. 38, 72-78. doi: 10.1016/j.cois.2020 02.003

Varanasi, A., Prasad, P. V. V., and Jugulam, M. (2016). "Chapter three impact of climate change factors on weeds and herbicide efficacy," in Advances in Agronomy, ed D. L. Sparks (London, UK: Academic Press), 107-146.

Vilà, M., Corbin, J. D., Dukes, J. S., Pino, J., and Smith, S. D. (2007). "Linking plant invasions to global environmental change," in Terrestrial Ecosystems in a Changing World. Global Change - The IGBP Series, eds J. G. Canadell, P. Pataki, and P. Pitelka (Berlin; Heidelberg: Springer), 93-102.

Walck, J. L., Hidayati, S. N., Dixon, K. W., Thompson, K., and Poschlod, P. (2011). Climate change and plant regeneration from seed. Global Change Biol. 17, 2145-2161. doi: 10.1111/j.1365-2486.2010.02368.x

Ward, S. M., Cousens, R. D., Bagavathiannan, M. V., Barney, J. N., Beckie, H. J., and Busi, R., et al. (2014). Agricultural weed research: a critique and two proposals. Weed Sci. 62, 672-678.

Wilson, J. R., Bacher, S., Daehler, C. C., Groom, Q. J., Kumschick, S., Lockwood, J. L., et al. (2020). Frameworks used in invasion science: progress and prospects. NeoBiota 62, 1-30. doi: 10.3897/neobiota.62.58738

Zhang, X., Wei, H., Zhao, Z., Liu, J., Zhang, Q., and Zhang, X. (2020) The global potential distribution of invasive plants: Anredera cordifolia under climate change and human activity based on random forest models. Sustainability, 12:1491.

Zimdahl, R. L. (2018). Fundamentals of Weed Science. London: Academic Press.

Ziska, L. H. (2016). The role of climate change and increasing atmospheric carbon dioxide on weed management: herbicide efficacy. Agricu. Ecosyst. Environ. 231, 304-309. doi: 10.1016/j.agee.2016.07.014

Ziska, L. H., Blumenthal, D. M., and Franks, S. J. (2019). Understanding the nexus of rising $\mathrm{CO} 2$, climate change, and evolution in weed biology. Invasive Plant Sci. Manag. 12, 79-88. doi: 10.1017/inp.2019.12

Conflict of Interest: The authors declare that the research was conducted in the absence of any commercial or financial relationships that could be construed as a potential conflict of interest.

Copyright (C) 2021 Sun, Kaleibar, Oveisi and Müller-Schärer. This is an open-access article distributed under the terms of the Creative Commons Attribution License (CC $B Y)$. The use, distribution or reproduction in other forums is permitted, provided the original author(s) and the copyright owner(s) are credited and that the original publication in this journal is cited, in accordance with accepted academic practice. No use, distribution or reproduction is permitted which does not comply with these terms. 